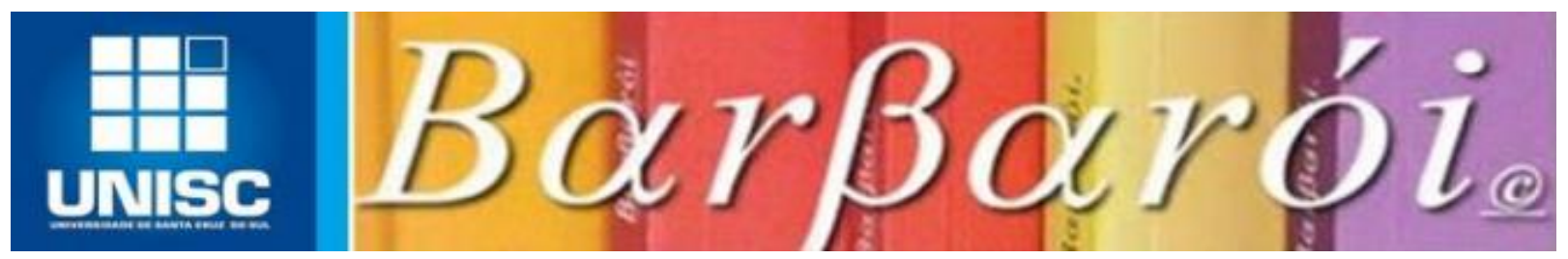

\title{
O ENSINO SUPERIOR EM SERVIÇO SOCIAL NO INÍCIO DO SÉCULO XXI: UM OLHAR DESDE A SOCIEDADE DO ESPETÁCULO
}

DOI: http://dx.doi.org/10.17058/barbaroi.v51i1.11219

\author{
Marta von Dentz \\ Pontifícia Universidade Católica do Rio Grande do Sul - PUCRS - Brasil
}

\section{RESUMO}

Este estudo objetiva produzir um campo de problematizações acerca dos desafios atuais que o Ensino Superior em Serviço Social vem enfrentando. Almeja sumarizar inquietações investigativas referentes ao Ensino Superior circunscrito em uma profissão cuja formação, no início do século XXI, se reconfigura de maneira acelerada, complexa e, como propomos aprofundar neste estudo, direcionada à "sociedade do espetáculo". Deste modo, toma-se como questão investigativa: Quais são as tendências do Ensino Superior em Serviço Social no início do século XXI? O que vem sendo engendrado no interior desta trama? Do ponto de vista metodológico, propõe-se a realização de um recorte analítico priorizando uma leitura diagonal dos dados obtidos junto ao Cadastro e-MEC. Compomos um levantamento dos cursos de graduação em Serviço Social no estado do Rio Grande do Sul enfatizando aspectos que fazem referência ao período de início dos cursos nas Instituições de Ensino Superior, as denominações das Instituições, a modalidade do Ensino, as vagas autorizadas, a situação do curso e a nota do Exame Nacional de Desempenho dos Estudantes tecendo contrapontos com a percepção teórica da sociedade do espetáculo desenvolvida pelo escritor francês Guy Debord. Encaminha-se, de forma preliminar, para o posicionamento estratégico da perda da qualidade do Ensino Superior, a acentuada mercantilização deste Ensino na entrada do século XXI, a decadência de Instituições de Ensino Superior presenciais. Do ponto de vista teórico, afirma-se que esse cenário tem sido reforçado em nosso tempo na medida em que a sociedade do espetáculo se intensifica.

Palavras-chave: Serviço Social. Ensino Superior. Estado do Rio Grande do Sul.

\section{INTRODUÇÃO}

"É necessário reconstruir uma cultura de debate e de crítica, marcada pela interação, pelo diálogo, pela leitura conjunta dos nossos trabalhos, pela capacidade de nos envolvermos numa conversa intelectual com os outros" (NÓVOA, 2015, p. 270).

A epígrafe evidenciada faz referência à palestra proferida no Congresso Europeu de Pesquisa Educacional em 2014. Na oportunidade, o pesquisador supracitado aprofundou a 
liberdade nas universidades, a premente necessidade de reconstruir a interação, de nos envolvermos numa conversa intelectual com os outros realizando uma leitura conjunta dos nossos trabalhos. Embora a ênfase aprofundada pelo autor faça referência à pesquisa no campo educacional, a escolha deste ponto de partida propõe enfatizar que, este estudo, se insere num espaço dialógico que enseja ser ampliado no sentido de reconstruir uma cultura de debate e de crítica (NÓVOA, 2015). Assim, este itinerário objetiva produzir um campo de problematizações acerca dos desafios atuais que o Ensino Superior em Serviço Social vem enfrentando. A pretensão, neste momento, é incipiente e inicial. Todavia, significativa, uma vez que almeja sumarizar inquietações investigativas referentes ao Ensino Superior circunscrito em uma profissão cuja formação, no início do século XXI, se reconfigura de maneira acelerada, complexa e, como propomos aprofundar neste estudo, direcionada à "sociedade do espetáculo" (DEBORD, 2003).

Referente ao Ensino Superior em Serviço Social, recentes slogans publicitários evidenciam, a saber: "Serviço Social - Bacharelado, várias vagas em setor público através de concursos"; "Bacharelado em Serviço Social - novo curso - universidade credenciada ao MEC - escolha a melhor universidade do Brasil"; "mensalidades até 60\% mais baratas"; “Cursos na área de Serviço Social - mensalidades por apenas R\$109,99”; "Serviço Social vá à unidade uma vez por semana - seu diploma agora dâ"; "meu sonho é fazer Serviço Social". Sem mencionar instituições, modalidades de ensino, entre outros aspectos, a busca rápida às publicidades relacionadas ao curso de Serviço Social são, no mínimo, provocativas e instigantes. Mencionam o vasto campo de atuação profissional em setores públicos, mensalidades acessíveis, facilidade em adquirir um diploma e a possibilidade de tornar o sonho de obter um diploma uma realidade. Assim sendo, interessa-nos interrogar: Como a formação dos estudantes em Serviço Social é posicionada nesses slogans publicitários? Que sentidos formativos e pedagógicos são engendrados no interior deles?

Ampliando este debate, recordamos a recente participação no VII Fórum Estadual de Supervisão de Estágio em Serviço Social/RS, ocorrido na Universidade de Santa Cruz do Sul entre 10 e 11 de agosto de 2017. Com presença de docentes, discentes, supervisores de estágio, Conselho Regional de Serviço Social da $10^{\circ}$ região (CRESS/RS), representante da Associação Brasileira de Ensino e Pesquisa em Serviço Social (ABEPSS), da Executiva Nacional de Estudantes de Serviço Social (ENESSO) entre outros participantes. Foi latente, neste fórum, o debate sobre os desafios presentes no Ensino Superior em Serviço Social. Referente aos docentes foram questionados métodos de ensino inadequados utilizados em sala de aula para discentes trabalhadores e sem tempo; a utilização de leituras pesadas e 
cansativas, de difícil compreensão; a desarticulação dos aportes utilizados na academia com a experiência adquirida nos campos de estágio. Referente aos discentes foram pontuados aspectos atinentes à dificuldade de interpretação textual, uma escrita frágil e desarticulada, à falta de leitura e de apropriação crítica, ao cansaço e falta de disposição para aprender, ao descomprometimento com a formação, com as responsabilidades da vida acadêmica, entre outros elementos debatidos abertamente (CRESS-RS/FESSS/RS, 2017).

$\mathrm{Na}$ mesma direção, é latente a preocupação existente na categoria profissional do Serviço Social frente ao crescente número de processos de extinção de cursos nesta área em Instituições de Ensino Superior presenciais privadas, comunitárias, filantrópicas, entre outras denominações. O aumento da oferta de cursos de Serviço Social a distância, com mensalidades ínfimas, exigências no processo de ensino flexíveis, têm atraído significativamente os jovens que buscam qualificação no Ensino Superior nesta área. Em contrapartida, os cursos presenciais passam por um processo de encolhimento, de reformulações curriculares, de diminuição do corpo docente, de propostas de um "ensino híbrido" em Serviço Social que, embora contestadas, estão ocorrendo. Deste modo questionase: $O$ que vem sendo criado no interior desta trama? $\mathbf{E}$ ainda, quais são as tendências do Ensino Superior em Serviço Social no início do século XXI?

A partir destes aspectos introdutórios, e de um contexto mais amplo que o envolve, propomos problematizar o Ensino Superior em Serviço Social no início do século XXI. Este estudo, muito mais que externalizador de angústias e de impressões de que o Ensino em Serviço Social está em decadência ou em momentos difíceis, provoca olhar o tempo presente desde a perspectiva de "reconstruir uma cultura de debate e de crítica" (NÓVOA, 2015), considerando que coesa "é a cultura de uma sociedade que muda devagar [...] em ritmo lento" (BAUMAN, 2012, p. 126). E, tendo a sapiência de que pensar crítica e dialeticamente, como nos recorda a história da dialética nos tempos em que a metafísica se tornou hegemônica, requer não raras vezes viver em espaços "subterrâneos” (KONDER, 2008, p. 13).

Frente a essas inquietações mencionadas, organizamos o presente estudo em duas seções. Na primeira seção produzimos um diagnóstico acerca do Ensino Superior em Serviço Social especificamente no estado do Rio Grande do Sul. Através do acesso ao Cadastro eMEC, como base de dados oficial de informações relativas às Instituições de Educação Superior e cursos de graduação do Sistema Federal de Ensino. Compomos um levantamento dos cursos de graduação em Serviço Social neste estado enfatizando aspectos que fazem referência ao período de início dos cursos nas Instituições de Ensino Superior, as denominações das Instituições, a modalidade do Ensino, as vagas autorizadas, a situação do 
curso e a nota do Exame Nacional de Desempenho dos Estudantes (ENADE). A seguir, na segunda seção, realizamos aproximações do diagnóstico produzido com a percepção teórica da "sociedade do espetáculo" desenvolvida pelo escritor francês Guy Debord e publicada pela primeira vez em 1967. Entendemos ser este, um estudo provocativo de um debate presente e latente entre os que se dedicam à formação dos novos profissionais em Serviço Social.

\section{Ensino Superior em Serviço Social no Estado do Rio Grande do Sul: um diagnóstico a partir do Cadastro e-MEC}

Consideramos rapidamente, a título de contextualização, que o surgimento das primeiras escolas em Serviço Social no Brasil ocorreram no período de 1936 a 1945. Em 1936 foi criado o primeiro curso na Escola de Serviço Social de São Paulo (incorporado à PUC-SP em 1972). Na sequência, em 1937, tem origem a Escola de Serviço Social do Instituto de Educação Familiar e Social, no Rio de Janeiro (agregada à PUC-RJ em 1946). “Em 1940, surge o Instituto de Serviço Social de São Paulo e no mesmo ano tem origem a Escola de Serviço Social de Pernambuco, a primeira do Nordeste, incorporada à UFPE em 1970”. Em 1944, foi fundada a Escola de Serviço Social da Bahia, em 1945 “a Escola de Serviço Social do Paraná (integrada à Pontifícia Universidade Católica do Paraná em 1969) e a Escola de Serviço Social de Porto Alegre, em 1945 (integrada à Universidade Católica em 1948)" (IAMAMOTO, 2017, p. 23). Neste sentido, ressaltamos a influência católica como prevalecente nas origens das primeiras escolas de Serviço Social no Brasil (IAMAMOTO, 2017).

As iniciativas do Estado na formação profissional brasileira em Serviço Social nas suas origens e se perpetuando na história desta profissão são de menor investimento. Recordamos, "as iniciativas partícipes do movimento da Escola Nova" como "marco inaugural do projeto de renovação educacional do país" (IAMAMOTO, 2017, p. 23). Assim, como iniciativa do Estado e influência dos movimentos em curso na época, são registradas as seguintes escolas: em 1937 - o Centro de Serviço Social da Escola de Enfermagem Ana Nery na Universidade do Brasil, hoje UFRJ; em 1940 - a Escola de Serviço Social de Manaus, agregada à universidade em 1962; em 1945 - a Escola de Serviço Social de Niterói, que se incorpora à Universidade Federal Fluminense, em 1980; em 1945 - a Escola de Serviço Social de Natal, agregada à Universidade Federal do Rio Grande do Norte, em 1969 (IAMAMOTO, 2017). Neste sentido destacamos que: 


\begin{abstract}
A formação em Serviço Social é de nível superior desde suas origens, sendo que a partir da década de 1970 foi inscrita no circuito universitário. Dispõe de diretrizes curriculares nacionais para o ensino de graduação propostas por nossas entidades representativas (Abess/Cedepss, 1996), aprovadas e reguladas pelo Estado. Elas norteiam os 567 cursos de graduação autorizados em agosto de 2012, 518 dos quais são privados $(91,4 \%)$ e 49 , públicos $(8,6 \%)$. Os 230 cursos à distância são exclusivamente privados e correspondem a $44,4 \%$ do conjunto dos cursos privados, enquanto os presenciais somam 288, ou seja, 55,6\% dos cursos privados (IAMAMOTO, 2017, p. 20).
\end{abstract}

A partir deste dado, de 567 cursos de graduação existentes no Brasil no segundo semestre de 2012, da prevalência histórica de um ensino privado, adicionando os cursos à distância neste debate, é que avançamos para as particularidades do Ensino Superior em Serviço Social no Estado do Rio Grande do Sul produzindo um diagnóstico a partir do Cadastro e-MEC ${ }^{1}$. Ressaltamos que o levantamento se refere aos cursos de graduação em Serviço Social neste estado, enfatizando aspectos que mencionam o período de início dos cursos nas Instituições de Ensino Superior (criação), as denominações das Instituições (federais, privadas, comunitárias, filantrópicas), a modalidade do Ensino (presencial ou à distância), as vagas autorizadas, a situação do curso (em atividade ou em extinção) e a nota do Exame Nacional de Desempenho dos Estudantes.

\title{
2.1 Levantamento das Instituições de Ensino Superior com cursos de Graduação em Serviço Social/RS
}

A criação dos primeiros cursos em Serviço Social no estado do Rio Grande do Sul, juntamente com as origens da profissão no Brasil, marcaram o início da segunda metade da década de 1945. A predominância de cursos ofertados por Instituições de Ensino Superior privados marcaram 61 anos de história neste estado. Uma vez que somente em 2006 tivemos o primeiro curso em Serviço Social em uma Universidade Federal. Sendo que logo, em 2007, há o início da oferta de cursos em Serviço Social à distância como podemos ver no Gráfico 1.

Gráfico 1: Criação dos cursos de graduação em Serviço Social/RS

\footnotetext{
${ }^{1}$ Os dados estão disponíveis em: http://emec.mec.gov.br/. Acesso em: 03 outubro 2017.
} 


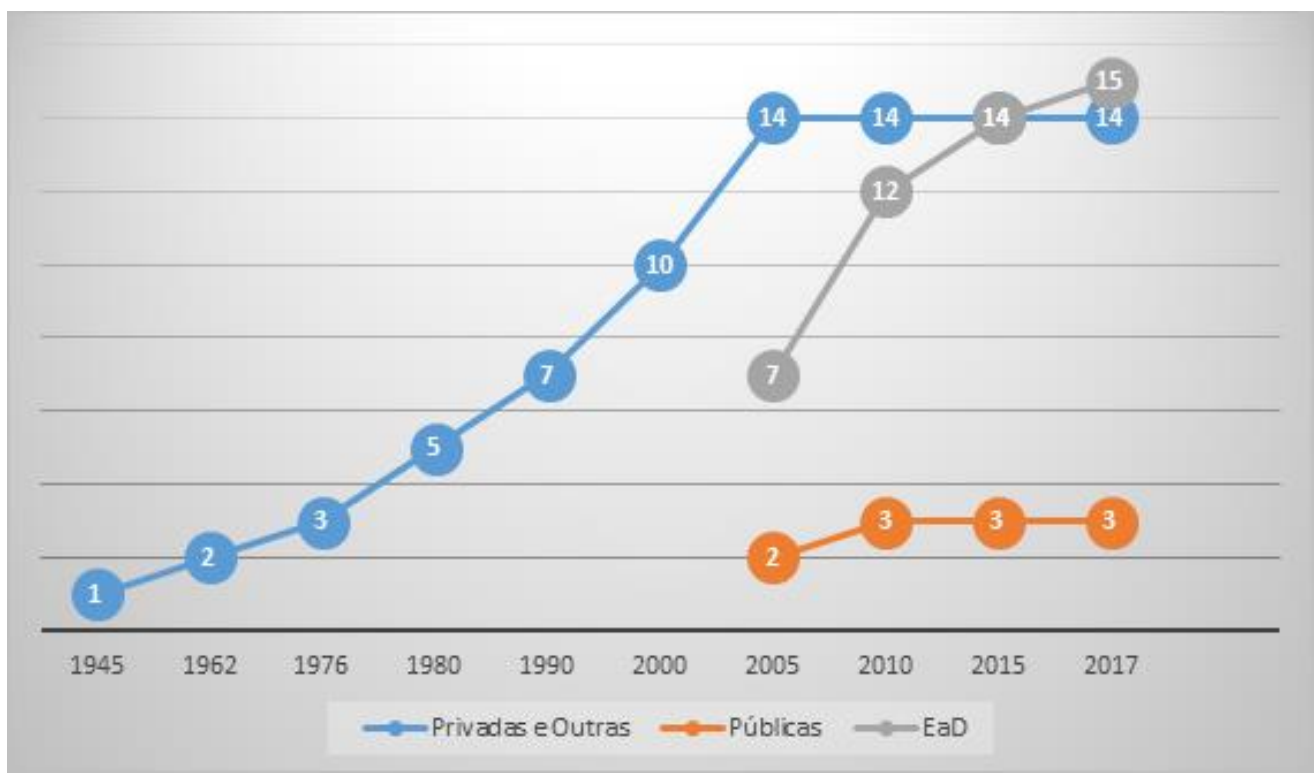

Fonte: Cadastro e-MEC (2017)

Passamos a detalhar, então, o início dos cursos no estado em tela: em 20 de março de 1945 tivemos a criação do Curso de Serviço Social pela, hoje conhecida, Pontifícia Universidade Católica do Rio Grande do Sul (PUCRS); seguindo, depois de 17 anos, em 23 de março de 1962 a Universidade Católica de Pelotas (UCPEL) passa a ofertar o curso; a Universidade de Caxias do Sul (UCS) ${ }^{2}, 14$ anos mais tarde, inicia o Curso em 08 de março de 1976; no início dos anos 1980, em 01 de agosto, a Universidade Luterana do Brasil (ULBRA) $^{3}$ passa a ofertar o curso no município de Canoas e em 14 de agosto de 1984 a Universidade do Vale do Rio dos Sinos (UNISINOS); em 04 de março de 1996 a Universidade Regional Integrada do Alto Uruguai e das Missões (URI) ${ }^{4}$ oferta o curso à comunidade e em 04 de março de 1997 a Universidade de Cruz Alta (UNICRUZ). Desde 1945 até o final da década de 1990 o estado do Rio Grande do Sul contava com sete Instituições de Ensino Superior privadas com cursos de Serviço Social espalhados pelas regiões.

No início dos anos 2000, entrada do século XXI, outras Instituições passaram a ofertar os cursos no estado pela iniciativa privada, a saber: em 28 de fevereiro de 2000 na Universidade de Santa Cruz do Sul (UNISC); em 01 de março do mesmo ano no Centro Universitário Franciscano (UNIFRA); em 02 de agosto de 2004 na Universidade de Passo Fundo (UPF).

\footnotetext{
2 Em 01 de março de 2011 a Universidade passa a ofertar o curso também no Campus de Vacaria/RS.

${ }^{3}$ Em 03 de agosto de 1999 a Universidade passa a ofertar o curso também no Campus de Cachoeira do Sul; em 01 de agosto de 2000 em Carazinho; em 02 de agosto de 2004 em Gravataí.

${ }^{4}$ Em 02 de agosto de 2004 a Universidade passa a ofertar o curso no Campus de São Luiz Gonzaga/RS.
} 
A partir de 2005 temos a entrada de modalidades diferenciadas de Ensino: em 22 de fevereiro de 2005 o curso passa a ser ofertado no Centro Universitário Metodista; em 16 de outubro de 2006 temos o primeiro curso de Ensino Superior em Serviço Social em âmbito federal no estado pela Universidade Federal do Pampa (UNIPAMPA); em 07 de fevereiro de 2007 temos o primeiro curso à distância ${ }^{5}$ no estado pela Universidade Anhanguera (UNIDERP) e no mesmo ano pela Universidade do Norte do Paraná (UNOPAR) em 12 de fevereiro.

Em 2008 temos a criação de mais quatro cursos ofertados na modalidade à distância: em 18 de fevereiro pela Universidade Paulista (UNIP); em 31 de março pela Universidade Luterana do Brasil (ULBRA); em 22 de abril pela Universidade de Santo Amaro (UNISA) e em 05 de maio pelo Centro Universitário Leonardo da Vinci (UNIASSELVI). Ainda neste ano o curso passou a ser ofertado pela Faculdade Ecoar (FAECO) em 26 de maio na modalidade presencial. Em 04 de fevereiro de 2009 o Centro Universitário Claretiano (CEUCLAR) oferta o curso e também, em 2009, a segunda Universidade Federal do estado passa a ofertar o curso em Serviço Social, em 17 de julho pela Federal do Rio Grande do Sul (UFRGS); seguida da Faculdade Anhanguera de Caxias do Sul em 03 de agosto de 2009 na modalidade presencial e privada.

A partir de 09 de agosto de 2010 o curso é ofertado pela Universidade Federal de Santa Maria (UFSM); seguida da oferta à distância pela Universidade Estácio de Sá (UNESA); pela Universidade Salgado de Oliveira (UNIVERSO) em 12 de setembro de 2010; pelo Centro Universitário Estácio de Ribeirão Preto em 20 de julho de 2011; pelo Centro Universitário de Maringá (UNICESUMAR) em 03 de fevereiro de 2014; posteriormente pelo Ensino presencial privado da FADERGS em 24 de fevereiro de 2014 e pelo Ensino à distância na Universidade do Sul de Santa Catarina (UNISUL), em 07 de abril de 2014. Os três últimos cursos ofertados são na modalidade à distância: em 01 de agosto de 2015 pelo Centro Universitário Internacional (UNINTER); em 03 de agosto do mesmo ano pelo Centro Universitário Planalto do Distrito Federal (UNIPLAN) e em 01 de fevereiro de 2017 pela Universidade Católica Dom Bosco (UCDB).

Recapitulando, atualmente o estado do Rio Grande do Sul conta com catorze Instituições de Ensino Superior que ofertam o curso em Serviço Social na iniciativa privada, comunitária, filantrópica entre outras denominações; três Instituições que oferecem o curso em âmbito federal e quinze Instituições privadas que ofertam o curso na modalidade a

5 "Cabe destacar que o primeiro curso de Serviço Social criado na modalidade de EaD assim o foi no ano de 2006” (PEREIRA; SOUZA; FERREIRA, 2017, p. 195).

Barbarói, Santa Cruz do Sul, n.51, p.<73-89>, jan/jun, 2017 
distância. O levantamento reafirma, de maneira detalhada, a predominância histórica do Ensino privado no estado em tela. A ausência histórica do Ensino Federal criado apenas em 2006 e se expandindo somente até 2010. A crescente oferta do Ensino privado na modalidade a distância. E, a ausência completa do Ensino em âmbito Estadual.

Neste sentido, reiteramos que a presença do setor privado não apenas na área do Serviço Social, mas na Educação Superior brasileira se perpetua historicamente. O Censo da Educação Superior de 2007 informou a existência de 2.281 IES, destas " $89 \%$ de natureza privada". Pontuamos também a predominância de instituições não universitárias, ou seja, que não precisam realizar pesquisa, somente transferir conhecimento. Vejamos que " $86,7 \%$ das IES encontram-se registradas como faculdades, enquanto as universidades e centros universitários respondem por $8 \%$ e 5,3\%". Lembrando que os centros universitários também não são obrigados à realização de pesquisa, “o que faz as IES não universitárias representarem mais de 90\% do total das IES existentes no país" (PEREIRA, 2009, p. 271).

A realidade do Ensino Superior em Serviço Social no Rio Grande do Sul na atualidade perpassa por reconfigurações até então não vistas. Além de sabermos que, o Ensino Superior e demais áreas sociais não são consideradas demandas do Estado e a responsabilidade fica para as instituições privadas ou públicas não estatais. Que essa estratégia política "abre precedentes para a desresponsabilização do Estado, a sua privatização e execução por instituições não estatais, o que foi concretizado ao longo dos anos 1990 e permanece em consolidação na entrada do século XXI" (PEREIRA, 2009, p. 271). Temos presente neste processo: o repensar dos currículos nesta área de Ensino, a atratividade virtual em detrimento da presencial, questionamentos e tensionamentos de docentes que possuem carreira e experiência no Ensino presencial privado que atualmente se encontra "ameaçado" em várias Instituições, a entrada forte de metodologias ativas no exercício pedagógico da sala de aula exigindo aperfeiçoamento dos docentes, entre outros elementos que aqui poderiam ser elencados, como por exemplo, a qualidade do Ensino em nossos tempos. Mais adiante, pontuamos a decadência do Ensino Privado presencial com cursos em extinção. Passamos, então, a destacar as vagas autorizadas pelo Ministério da Educação (MEC) nos cursos de Serviço Social vigentes nesta territorialidade.

\subsection{Vagas autorizadas para os Cursos de Serviço Social/RS}

Anteriormente, nos detemos em perceber a evolução e os contornos que o Ensino Superior em Serviço Social foi tomando ao longo da história no estado do Rio Grande do Sul. 
Neste momento, passamos a elucidar as vagas autorizadas para cada IES na atualidade. O Quadro 1, foi compilado a partir das informações contidas no Cadastro e-MEC.

Nos preocupamos em dar visibilidade a cada Instituição de Ensino Superior com suas respectivas vagas autorizadas. Fica notório a mínima oferta de vagas no Ensino público; uma oferta um pouco maior no Ensino privado presencial; e, uma larga oferta no Ensino privado EaD. Praticamente o Ensino a distância dispara na oferta de vagas autorizadas. Portanto, este Ensino aparece "como uma via extremamente lucrativa para a expansão capitalista e a formação de intelectuais necessários à ordem burguesa. Lembramos que a criação das primeiras Universidades Abertas ocorreu ainda na década de 1970 e sua expansão mundial a partir de então" (PEREIRA, 2009, p. 270). De imediato, passamos e enfatizar, neste diagnóstico, o desempenho dos cursos de Serviço Social no Enade, consoante consulta ao Cadastro e-MEC.

Quadro 1: Vagas autorizadas nos cursos de Serviço Social/RS

\begin{tabular}{|c|c|c|}
\hline Instituição de Ensino Superior & Vagas autorizadas & Modalidade \\
\hline Públicas presenciais: & & \\
UNIPAMPA & 50 & Presencial \\
UFRGS & 30 & \\
UFSM & 50 & \\
\hline TOTAL & 130 & Presencial \\
\hline Privadas presenciais: & 200 & \\
FADERGS & 120 & \\
IPEA & 100 cada IES & \\
FAECO, ULBRA, UCPEL & 70 & \\
ANHANGUERA CAXIAS DO SUL & 60 & \\
UNISINOS & 55 & \\
PUC-RS & 50 cada IES & \\
UNISC & 40 & \\
URI, UPF, UCS & 30 & \\
UNIFRA & $\mathbf{1 . 2 5 5}$ & \\
UNICRUZ & & \\
TOTAL & 47.880 & \\
A distância \\
Privadas a distância: & 21.150 & \\
UNIP & 16.800 & \\
UNOPAR & 5.050 & \\
UNIDERP & 4.000 & \\
UNESA & 4.000 & \\
ESTÁCIO RP & 3.000 & \\
UNIPLAN & 2.300 & \\
ULBRA & 2.000 & \\
UNINTSA & & \\
UNIVERSO & & \\
\hline
\end{tabular}




\begin{tabular}{|c|c|c|}
\hline $\begin{array}{c}\text { UNIASSELVI } \\
\text { CEUCLAR } \\
\text { UNISUL, UCDB }\end{array}$ & $\begin{array}{c}1.300 \\
900 \\
200 \text { cada IES }\end{array}$ & \\
\hline TOTAL & $\mathbf{1 1 6 . 0 4 0}$ & \\
\hline
\end{tabular}

Fonte: Cadastro e-MEC (2017)

\subsection{Desempenho dos estudantes de Serviço Social no Enade/RS}

Relembramos que o Exame Nacional de Desempenho dos Estudantes ocorre para avaliar o rendimento dos estudantes em nível de graduação. O exame é aplicado para alunos ingressantes e concluintes e avalia os conteúdos programáticos dos cursos em que estão matriculados. A prova é obrigatória para os alunos selecionados e é condição indispensável para a emissão do histórico escolar. A primeira aplicação do Enade no Brasil ocorreu em 2004 e sua periodicidade é trienal para cada área do conhecimento.

O cálculo do indicador de qualidade da Educação Superior aferido pelo Enade é composto pelo: conceito Enade, conceito preliminar de curso (CPC) e o índice geral de cursos avaliados da Instituição (IGC). Assim, podemos pontuar que nas buscas ao Cadastro e-MEC identificamos, do montante de 32 IES que ofertam o curso de Serviço Social no estado do Rio Grande do Sul: uma IES privada presencial com nota máxima no Enade, representando 3,1\%; duas federais e seis privadas presenciais com nota quatro, representando $25 \%$; cinco IES privadas presenciais e uma privada a distância com nota três, representando 18,75\%; oito privadas a distância com nota dois, correspondendo a 25\%; uma federal com nota um, 3,1\%; e, duas privadas presencias com mais seis a distância sem conceito, correspondendo a $25 \%$ da totalidade.

Após conhecermos o percurso histórico dos cursos de Serviço Social no estado do Rio Grande do Sul, visualizarmos as vagas autorizadas para os cursos, passamos a enfatizar o desempenho dos estudos, o rendimento dos mesmos consoante informações atualizadas do Cadastro e-MEC:

Quadro 2: Desempenho dos estudantes de Serviço Social no Enade em IES do RS

\begin{tabular}{|c|c|}
\hline \multicolumn{1}{|c|}{ Instituições de Ensino Superior } & Enade \\
\hline Públicas presenciais: & \\
$\rightarrow$ UNIPAMPA e UFSM & 4 \\
$\rightarrow$ UFRGS & 1 \\
\hline
\end{tabular}




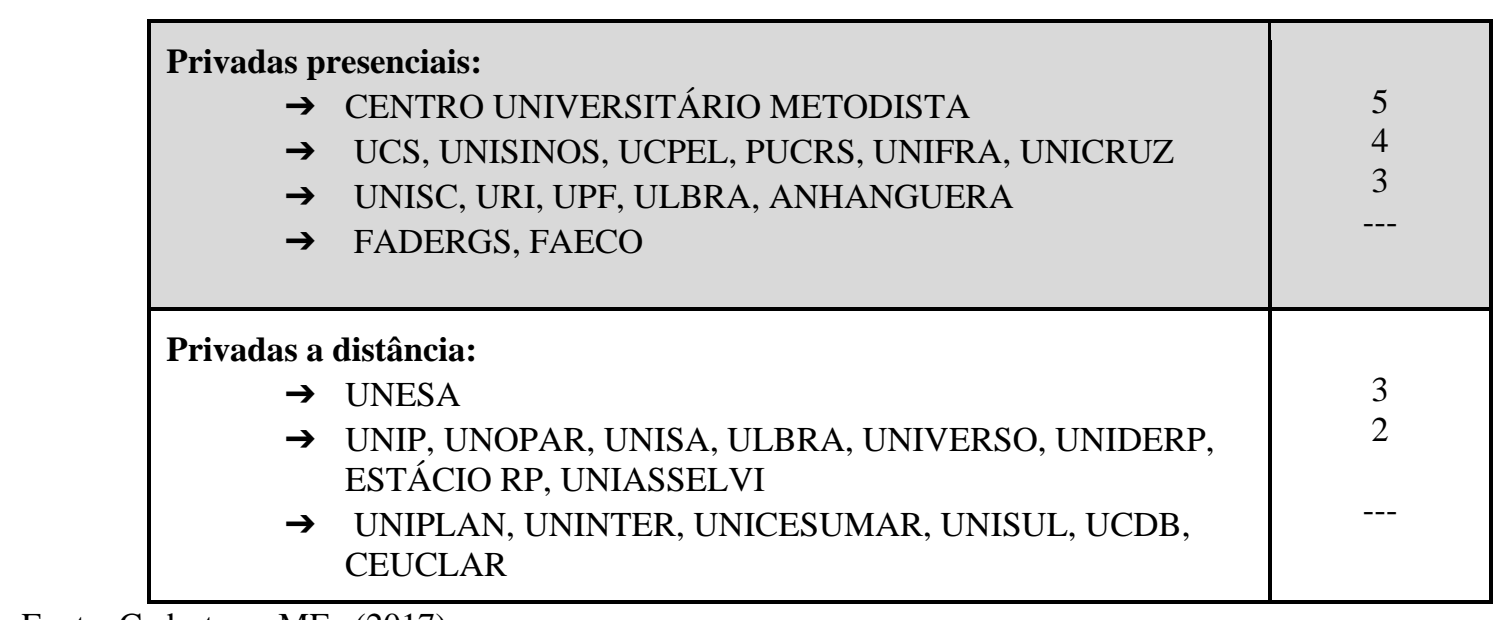

Fonte: Cadastro e-MEc (2017)

Destacamos a forte presença de cursos sem conceito no Enade principalmente de cursos a distância o que se relaciona com a recente oferta destes cursos. Também pontuamos forte índice do conceito dois em cursos não presenciais. Reiteramos a importância de olhar os conceitos trazidos a partir da realidade Institucional de cada curso. Neste momento, não avançaremos em um debate mais detalhado sobre esses aspectos, apenas alertamos esta necessidade. Assim, avançamos neste estudo contemplando informações referentes ao último item deste diagnóstico.

\subsection{Cursos de Serviço Social em Extinção/RS}

Ao consultarmos o Cadastro e-MEC notamos uma significativa presença de cursos em Serviço Social em extinção. Na base de dados aparece "situação do curso" detalhada como "em atividade" ou "em extinção". Ressaltamos que os cursos em extinção não foram pontuados nas informações levantadas até este momento do estudo. Todavia, ao resgatarmos a criação e início dos cursos visualizados no Gráfico 1, adicionando os cursos em extinção, temos uma nova realidade a ser pensada. Assim, primeiramente elencamos o quadro de cursos nesta situação para depois contrastarmos com os dados anteriores.

Quadro 3: Cursos de Serviço Social em Extinção no Estado do Rio Grande do Sul

\begin{tabular}{|c|c|c|c|}
\hline Instituição de Ensino Superior & Modalidade & $\begin{array}{c}\text { Vagas } \\
\text { autorizadas }\end{array}$ & $\begin{array}{c}\text { Situação do } \\
\text { Curso }\end{array}$ \\
\hline $\begin{array}{c}\text { Universidade Regional do Noroeste do Estado do Rio } \\
\text { Grande do Sul (UNIJUI) }\end{array}$ & Presencial & 40 & Em extinção \\
\hline
\end{tabular}




\begin{tabular}{|c|c|c|c|}
\hline Faculdades integradas Machado de Assis (FEMA) & Presencial & 110 & Em extinção \\
\hline Faculdade Dom Bosco de Porto Alegre (FDB) & Presencial & 200 & Em extinção \\
\hline $\begin{array}{c}\text { Faculdade de integração do Ensino Superior do Cone Sul } \\
\text { (FISUL) }\end{array}$ & Presencial & 50 & Em extinção \\
\hline $\begin{array}{c}\text { Universidade Luterana do Brasil (ULBRA) Carazinho, } \\
\text { Gravataí, Cachoeira do Sul. }\end{array}$ & Presencial & 100 & Em extinção \\
\hline Total: 7 cursos em extinção em 5 IES & & 500 & \\
\hline
\end{tabular}

Fonte: Cadastro e-MEC (2017)

Os cursos criados pela ULBRA são de: 1999 em Cachoeira do Sul, 2000 em Carazinho e 2004 em Gravataí; da FISUL foi criado em 2008 e aparece como "em desativação ou extinção voluntária"; da Faculdade Dom Bosco foi criado em 2010; da FEMA foi criado em 2005 em Santa Rosa e da UNIJUI foi criado em 2003. Todos em modalidade presencial. A partir deste panorama, fizemos o contraponto com os cursos em atividade mencionados no início do estudo e temos então um prognóstico para os próximos anos.

Gráfico 2: Prognóstico dos Cursos de Serviço para os próximos anos no Estado do RS

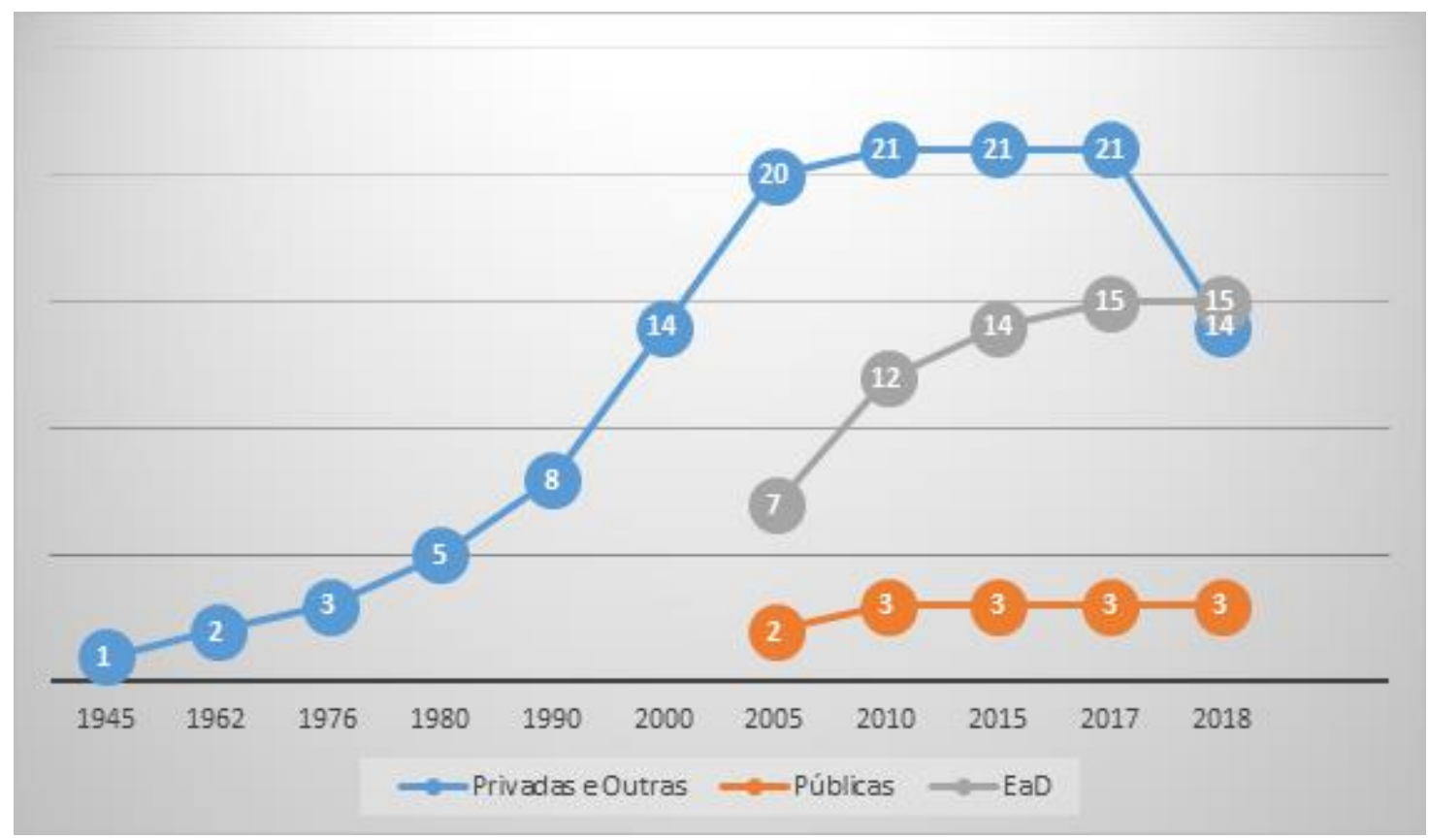

Fonte: e-MEC (2017)

Incluímos, no Gráfico 2, os cursos em extinção atualmente. Os incluímos no respectivo ano da criação do curso. O que salientamos com este contraponto é o fato de termos, ao longo da história, uma curva crescente do Ensino privado em Serviço Social presencial que atualmente, sobretudo nos próximos anos, tende a cair uma vez que temos o índice de sete cursos em processo de extinção e o enfraquecimento da modalidade presencial 
de um modo geral. Temos um número de Instituições que ofertam o Ensino a distância ultrapassando o número de Instituições que ofertam o ensino presencial. Esta curva parece ser assíntota, uma vez que se incluirmos as vagas autorizadas por esta modalidade temos uma disparada incomparável. Neste sentido, se faz oportuno retomar os questionamentos iniciais deste estudo: o que vem sendo engendrado no interior dessa trama? Quais são as tendências do Ensino Superior em Serviço Social no início do século XXI? Há perspectivas de rupturas e alterações possíveis neste prognóstico?

\section{O Ensino Superior em Serviço Social: um olhar desde a sociedade do espetáculo}

As informações elencadas até o momento neste estudo oportunizam problematizações significativas e necessárias. O diagnóstico realizado acerca do Ensino Superior em Serviço Social no estado do Rio Grande do Sul nos provoca e nos inquieta uma vez que as tendências, neste Ensino, na entrada do século XXI, exigem uma leitura crítica e um exercício intelectual aprofundado. Assim, retomamos o entendimento de que, durante o século XX, o direito à educação fez parte de grandes lutas e movimentos sociais. Já nos últimos tempos, "com a repetição sistemática do princípio da educação e formação ao longo da vida, a educação deixou de ser um direito e transformou-se num dever" (NÓVOA, 2015, p. 268). Tornou-se comum o entendimento de que cada indivíduo tem a obrigação de prover sua formação ao longo da vida para atingir níveis diferenciados de empregabilidade. E a Universidade foi incorporando fortemente essa ideia.

Outrossim, percebemos que o Ensino Superior em Serviço Social, a partir das abordagens anteriores, é permeado por características fortes do tempo presente. Um tempo que "sem dúvida...prefere a imagem à coisa, a cópia ao original, a representação à realidade, a aparência ao ser" (DEBORD, 2003, p. 13). Esse tempo, que não começou agora, mas que se intensificou sobremaneira na atualidade é definido pelo escritor Guy Debord como uma sociedade do espetáculo. Para o leitor marxista, “o espetáculo [...] é o resultado e o projeto do modo de produção existente. Ele é o coração da irrealidade sob todos as suas formas particulares de informação ou propaganda, publicidade ou consumo direto" (DEBORD, 2003, p. 15).

Ao que indicam as informações sobre o Ensino Superior em Serviço Social no estado estudado e que podem ser ampliadas para o Ensino Superior brasileiro: a Educação Superior aparece como um produto a ser consumido. A imagem, a representação, a aparência, a propaganda, a oferta facilitada são elementos muito presentes. Uma mercadoria interessante, 
um produto a ser consumido consoante a necessidade de quem a busca. Uma realidade, de fato, distante de compreender o Ensino Superior como um direito de todos (BRASIL, 1988).

Ressaltamos inclusive a perda do sentido crítico na sociedade do espetáculo. O resgate ao debate e a construção de uma cultura crítica ficam cada vez mais desafiadores uma vez que o "sentido crítico se dissolveu" na medida em que a sociedade do espetáculo foi se intensificando (DEBORD, 2003, p. 23). Consequentemente, “o espetáculo na sociedade representa concretamente uma fabricação de alienação" (DEBORD, 2003, p. 26). Em outras palavras, ele é uma "vedeta do consumo" que permite às pessoas encontrarem a felicidade (DEBORD, 2003, p. 44). Neste processo, pouco importa a qualidade do que se consome, pelo contrário, a satisfação se sobrepõe. Então, temos ofertas ampliadas de vagas para serem consumidas a vontade, com propostas sedutoras, oferecendo ao final um título honroso. $\mathrm{O}$ sentido crítico se perde e, por consequência, a alienação se amplia consideravelmente.

Nesta perspectiva, outro fator que importa ser lembrado é de que "a história que está presente em toda profundidade da sociedade tende a perder-se na superfície" (DEBORD, 2003, p. 117). Na sociedade do espetáculo, o tempo passado já não é mais, agora é a vez do nosso tempo. Do ponto de vista do Ensino em Serviço Social, podemos destacar que os movimentos internos realizados pela profissão, seu percurso histórico de enfrentamentos e de resistências já não são mais, já passaram. É a história se perdendo na superfície de uma sociedade que "curte" novos tempos. "É o tempo consumível que regressa à vida cotidiana [...] a paralisia da história e da memória" (DEBORD, 2003, p. 127).

Vejamos que o Ensino Superior em Serviço Social é atravessado majoritariamente por aquilo que a profissão vem definindo como "mercantilizado". Com condições de trabalho docente precárias, uma formação cada vez mais frágil em qualidade e, sobretudo, "não ancorada no tripé ensino, pesquisa, extensão" (PEREIRA; SOUZA; FERREIRA, 2017, p. 187). Pelo contrário, cada vez mais distante da pesquisa, do questionamento, da coletividade, da criticidade.

De modo que, o diagnóstico produzido do Ensino Superior em Serviço Social no estado do Rio Grande do Sul, indica para um Ensino fortemente permeado pelos condicionantes da sociedade do espetáculo, envolto de slogans criativos e instigantes, oferecendo oportunidades para todos os interesses subjetivos, sedutor e propositor de felicidade, facilitador da vida, dinâmico e rápido.

\section{Proposições finais}


Retomando a objetividade deste estudo pontuamos que o Ensino Superior em Serviço Social na entrada do século XXI apresenta um cenário, desafiador como também provocativo. Desafiador, sobretudo pelo fato da indissociabilidade do Ensino, da pesquisa e da extensão, estabelecida no artigo 207 da Constituição de 1988, dificilmente poder ser atendida por grande parte das Instituições do Ensino Superior mencionadas uma vez que não reúnem condições para desenvolver, principalmente, pesquisa (SILVA, 2001). Desafiador por tornar, cada vez mais distante, a concretização do Ensino Superior como um direito a ser acessado com qualidade.

Outro entendimento presente no interior desta trama é de que temos um vazio de significados que afeta tanto os estudantes como os docentes. O Ensino Superior, sobretudo privado, vem tratando os jovens, estudantes que dele se aproximam como clientes. Um Ensino que corteja o mundo dos seus clientes, que diverte, que atrai, quando deveria oferecer alternativas para conhecer outros mundos, para refletir melhor o que é o mundo do trabalho e, sobretudo, a vida.

O Ensino Superior em Serviço Social, fundamentado pela perspectiva crítica, historicamente conhecido como frente de resistência e enfrentamento aos desdobramentos do capital, está inserido nas protoformas da sociedade do espetáculo, permeado por seus condicionante e desafiado a reconstruir uma cultura do Ensino a partir do debate e da crítica e de um dialogo intelectual com os outros.

\title{
HIGHER EDUCATION IN SOCIAL WORK AT THE BEGINNING OF THE XXI CENTURY: A LOOK FROM THE SOCIETY OF SPECTACLE
}

\begin{abstract}
This study aims to produce a field of problematizations about the current challenges that Higher Education in Social Work has been facing. It aims to summarize investigative concerns regarding Higher Education, which is limited in a profession whose formation, at the beginning of the XXI century, is reconfigured in an accelerated, complex way and, as we propose to deepen in this study, directed to the "society of the spectacle". In this way, it is taken as an investigative question: What are the trends of Higher Education in Social Work at the beginning of the XXI century? What has been engendered within this plot? From the methodological point of view, it is proposed to perform an analytical cut prioritizing a diagonal reading of the data obtained from the e-MEC Register. We compose a survey of undergraduate courses in Social Work in the state of Rio Grande do Sul emphasizing aspects that refer to the period of beginning of the courses in Higher Education Institutions, the denominations of the Institutions, the modality of the Teaching, the vacancies authorized, the situation of the course and the note of the National Student Performance Examining counterpoints with the theoretical perception of the society of the spectacle developed by the French writer Guy Debord. The strategic positioning of the loss of the quality of Higher Education, the marked commercialization of this Teaching at the entrance of the XXI century,
\end{abstract}


the decadence of presential Institutions of Higher Education, is referred in a preliminary way. From the theoretical point of view, it is said that this scenario has been reinforced in our time as the society of the spectacle intensifies.

Keywords: Social Work. Higher education. State of Rio Grande do Sul.

\section{REFERÊNCIAS}

BAUMAN, Zygmunt. Ensaio sobre conceito de cultura. Rio de Janeiro, Zahar, 2012.

BRASIL. Constituição (1988). Constituição da República Federativa do Brasil. Brasília, DF: Senado Federal: Centro Gráfico, 1988.

CRESS-RS/FESSS. VII Encontro do Fórum Estadual de Supervisão de Estágio em Serviço Social. Supervisão direta no estágio curricular em Serviço Social: desafios à formação e ao trabalho profissional. Santa Cruz do Sul: Unisc, 2017.

DEBORD, Guy (1931-1994). A sociedade do espetáculo. Editoração, tradução e versão para eBook: eBooksBrasil.com. Fonte digital em pdf: www.geocities.com/projetoperiferia, 2003.

KONDER, Leandro. O que é dialética. São Paulo: Brasiliense, coleção Primeiros Passos, 2008.

IAMAMOTO, Marilda Villela. 80 anos do Serviço Social no Brasil: a certeza na frente, a história na mão. Serv. Soc. Soc., São Paulo, n. 128, p. 13-38, jan./abr. 2017.

NÓVOA, António. Em busca da liberdade nas universidades: para que serve a pesquisa em educação? Educ. Pesqui., São Paulo, v. 41, n. 1, p. 263-272, jan./mar. 2015.

PEREIRA, Larissa Dahmer. Mercantilização do ensino superior, educação a distância e Serviço Social. Rev. Katál. Florianópolis v. 12 n. 2 p. 268-277 jul./dez. 2009.

PEREIRA, Larissa Dahmer; SOUZA, Andréa Cristina Viana de; FERREIRA, Andreza Telles dos Santos. Ensino Superior mercantilizado e seus impactos para o perfil profissional de Serviço Social. In: Educação e Serviço Social: subsídios para uma análise crítica. Vânia Cardoso da Motta e Larissa Dahmer Pereira (Orgs). 1 ed. Rio de Janeiro: Lumen Juris, 2017.

SILVA, Alberto Carvalho da. Alguns problemas do nosso ensino superior. Estudos Avançados 15 (42). Educação Superior, 2001.

\section{Sobre o autor}

Marta von Dentz é Doutoranda em Servico Social pela Pontificia Universidade Catolica do Rio Grande do Sul; Mestre em Educacao pela Universidade Federal da Fronteira Sul; 
Bacharel em Servico Social pela Universidade do Oeste de Santa Catarina. Endereço eletrônico: martavondentz@gmail.com 